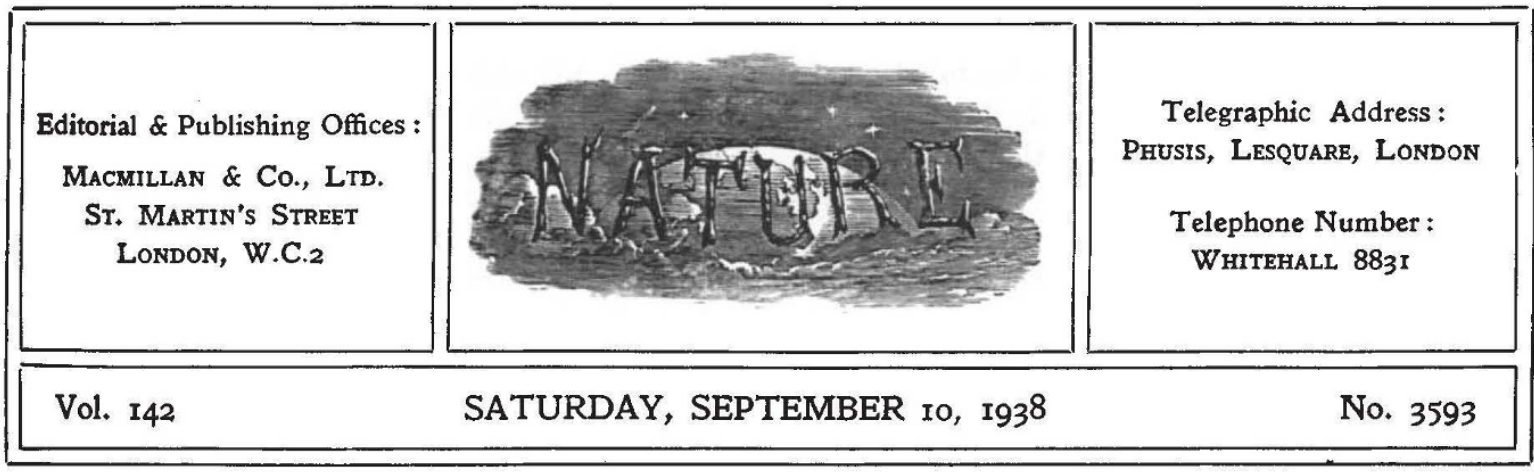

\title{
Native Problems in Northern Rhodesia*
}

$\mathrm{T}^{\mathrm{H}}$ HE native question, as it manifests itself in Northern Rhodesia, illustrates forcibly the fallacy of applying a general proposition indiscriminately to any specific group of tribal conditions among African, and more especially Bantu, peoples, when an attempt is made to solve the difficulties which arise out of the cultural contacts of white and black. Throughout the greater part of British Africa, 'indirect rule' has now been accepted as the fundamental principle of policy in administering native affairs. It was adopted in Northern Rhodesia in part by an ordinance of 1929, and more fully in an ordinance of 1936. Although it would be more than hazardous to attempt to formulate a final judgment arter so brief a period of trial, there are indications that any measure of success that has been achieved by the intro. duction of this system is of so qualified a character as to raise question whether it is fully suited to the temperament of the people and the development of their institutions.

This view receives support from the recently published report by Sir Alan W. Pim and Mr. S. Milligan on the financial and economic position in Northern Rhodesia. The conditions among the native population there described are such as would certainly seem to call for a considerable modification of administrative methods in the light of a more intensive study of circumstances than they have received.

It is perhaps scarcely necessary to recall that indireot rule has for its objectives, first to secure that administration of the affairs of a native people should be fully in accord with native ideas

- Report of the Commission Appointed to Enquire into the Financial and Economic Position of Northern Rhodesia. Pp. xi +365 . I'London: H.M. Stationery Office, 1938.) 78. net. and institutions; and secondly, to foster the development of those institutions, while ensuring that the initiative and sense of responsibility, which are essential to cultural advancement, shall not be undermined by too great dependence upon the paternal offices of white administration. Conditions in Northern Rhodesia are adverse to the attainment of both these objects. Among the seventy-three different tribes in the territory, tribal organization has disintegrated almost completely. Tribal boundaries are sometimes illdefined or have been disregarded, while in some instances the paramount chief of a tribal unit lying partly within British jurisdiction, himself lives outside the political boundary under another power. Intermarriage has blurred tribal distinctions, while some tribes form too small a unit to warrant a separate organization. Yet tribal distinctions cannot be ignored, even though they are confused. The tribes are too heterogeneous in origin to make fusion a practicable solution. Even in Barotseland, it is only the political dominance of one racial group, the Barotse, over all the others of the Barotseland plain, which has made possible the organization of a system of native rule.

Further, under the system of direct rule which has obtained for many years, the tribesmen have lost the habit of self-government, the initiative, and the self-reliance, which indirect rule demands. Nor are the pecuniary inducements now offered adequate to take the place of tribal interests as incentives to the performance of the functions of tribal administration, while the recently instituted native treasuries are inadequately financed. Hence expenditure within the native reserves is limited, and what may be regarded as 'public works', so far as that term is appropriate to tribal conditions, 
which have aroused the interest of the native and reconciled him in some measure to taxation elsewhere, in Northern Rhodesia are ineffective as a means of stimulating participation in self-rule.

Some of these defects might be remedied. A more adequate financial provision is not beyond the bounds of possibility, now that the economic position holds out hope of improvement. Such a measure, however, involves the somewhat doubtful assumption that the disintegration of the tribal system has not gone too far, and that the disinclination, or disability, to undertake responsibility for tribal control can be overcome. It is a question whether in Northern Rhodesia geographical, social and economic conditions, combined with native tradition in mode of life, do not demand a more drastic system of tutelage than can be exercised through a system which depends upon native institutions and trusts to a lightly regulated native culture to work out its own salvation.

In Northern Rhodesia, while an immense tract of land is potentially arable, the amount which is naturally fertile is relatively small. The native reserves are overcrowded : in some parts there are no inhabitants at all, while in others the density of population may rise to 60 per square mile, or in fishing areas to so much as 80 per square mile. The ill-effects of this irregularity of distribution and overcrowding are aggravated by the native mode of life. Except in Barotseland the people are not, as a rule, keepers of cattle. They live by agriculture or by fishing. The rivers and lakes are in danger of being over-fished, and the methods of agriculture are both destructive and wasteful. Frequently shifting plots are fertilized by burning off the bush and forest. This, combined with the inroads on forest trees made by the unregulated demands for timber of the mines and sawmills, has led to serious deterioration of the soil and forest resources of the country. In parts, sixty years will be required for recovery.

Since agriculture rises to no more than subsistence level, the imposition of taxation has forced the native to sell his one commodity-his labour. This has given rise to other and no less serious problems. Within Northern Rhodesia, virtually the only industries employing labour in any numbers are mining and the sawmill; both these industries, more especially mining, have encouraged the native to settle with his wife and family near his work, creating a population of urbanized and detribalized individuals, who are ill- housed, for whom the provision of educational facilities and medical attention is inadequate, and for whom, in short, there is an almost complete lack of social services, and, a more serious omission, towards whom there is no settled policy. At the same time, the labourer who seeks employment outside the territory suffers disabilities owing to the lack of a properly organized system of recruiting, with provision for conservation of pay, and of arrangements for transport and its cost.

Of the wise, and on the whole moderate, recommendations of the Commission, the most fundamental and far-reaching is the suggestion that the native reserves should be enlarged and a Native Lands Trust created on the lines which have been followed elsewhere. This measure would permit of future expansion, as necessary, and would interfere little, if at all, with any prospects of white settlement. It is evident, however, that for a genera. tion or more, advancement must be limited to the building up of a self-supporting, and ultimately locally administered, agricultural community.

Taking all these factors into account-the lack of tribal organization, the unsuitability of native culture or mode of life, without stringent regulation and much training, to the geographical and economic conditions of the country, and the consequent lack of opportunity for the development of native culture along its own lines, coupled with the dangers of urbanization-question must arise whether indirect rule, undiluted, provides the most suitable machinery for the prolonged period of tutelage with which the administration of native affairs would seem to be faced. Reactionary as it may be in the eyes of those who whole-heartedly support the introduction of indirect rule as the sanest and most advantageous system for the well-being of the native of Africaas it undoubtedly is in most instances-it is a question for serious consideration whether it would not be to the advantage of the native and of the future of Northern Rhodesia, if a measure of direct control were reintroduced with a staff of white officers, trained in an understanding of the institutions of backward peoples and their ways of thought, whose duties, in addition to supervision and discipline, should include the guidance of their wards along the lines of a policy of advancement framed in accordance with their mentality and cultural outlook.

The field of the Pim Commission on Northern Rhodesia being limited by its terms of reference to the financial and economic position, the policy 
of native administration as such is not within the scope of its report. Lest, however, it should be thought that the view here taken of the implication of the facts recorded by the Commission is unduly pessimistic, it may be mentioned that after these comments had been written, there came to hand a brief report of Sir Alan Pim's opening remarks in a discussion at the Royal Anthropological Institute on indirect rule in Northern Rhodesia. The view of the tribal situation, as it affects administration, then taken by Sir Alan, is in substantial agreement with that here expressed. $\mathrm{He}$ appears, however, to contemplate the possibility of modifying the system in such a manner as to meet the administrative difficulties. $\mathrm{He}$ poses four questions for the consideration of the anthropologist, in which he asks how indirect rule can best be made to subserve the ideals of native development and of modern government, in view of the rapid changes in native custom that are taking place, and the mixed populations growing up in industrial areas.

Sir Alan's questions are framed in terms which raise issues far wider in application than to Northern Rhodesia alone. In effect, he asks for a scheme of present and future policy, affecting the whole of British Africa in which indirect rule is now applied, based upon an intensive scientific study of native tribal culture and institutions. Is anthropology prepared with a reply?

\section{Medieval Calendars}

\section{Le Nombre d'Or:}

Etude de Chronologie Technique suivie du Texte de la Massa Compoti d'Alexandre de Villedieu. Avec Traduction et Commentaire par W. E. Van Wijk. Pp. $\mathrm{x}+158+11$ plates. (La Haye : Martinus Nijhoff, 1936.) 10 florins.

\begin{abstract}
A LEXANDER OF VILLEDIEU in Normandy was born at that town about 1170 ; at the time of his death at some unknown date, he was canon of a church at Avranches. As an educator of the young he adopted an original method. This consisted in reducing all rules to a metrical form which the pupil was required to commit to memory. A Latin grammar, the doctrinale of about 1199 , had a great vogue and was followed by an encyclopædic work, the ecclesiale, on the same metrical lines. The "Massa Compoti", a work on the calendar, runs to 509 lines and dates from 1200 .

This is a passage $(65-69)$ which has a familiar parallel in all languages :

\section{Junius, Aprilis, September necne November terdenos numerant continuantque dies ; praeter quos omnes uno retinent sibi plures. Sed tenet in numero viginti Februus octo, cui, si bissextus fuerit, superadditur unus.}

In a note on this passage, it is mentioned that the equally familiar legend, according to which this distribution of days is due to the interference of Augustus, from motives of jealousy, with the original assignment of Julius Cæsar, has no known classical authority. It is attributed to the invention of Sacrobosco.

These lines (49-52) may serve as a definition of the Golden Number :
Ignorans numerum qui lunae praedicat ortum, per denos nonos Domini dispertiat annos, adjungens unum; quicquid superest notat illum ; quando nil restat, decimum nonum fore constat.

It might have seemed simpler to add the unit to the remainder instead of adding it to the date.

The "Massa Compoti" owes its importance to the fact that it contains the first mention of the aureus numerus, which supersedes the epacts and other contrivances in earlier use for the calculation of the ecclesiastical new moon. The Latin text here reproduced is based on a collation of eighteen MSS., two at Utrecht, two in the Bodleian, four at Paris and the rest at Erfurt. It is followed by critical notes, a French translation and a detailed commentary.

This work of scholarship is preceded by a discussion of the earlier history of the problem of adapting dates defined in terms of lunar months to the Julian calendar, for this is what the fixing of Easter required. In a rather vague and ineffective minute addressed to Alexandria, the Nicene Council of 325 enjoined the practice of that church. But the use followed at Rome depended on a luni-solar cycle of 84 years, which has nothing in accuracy to compensate for its inconvenient length; this continued until the sixth century at Rome, until the eighth in England, and found its last refuge in Ireland. For the practice at Alexandria a conjectural reconstruction is necessary. According to that offered here, the Metonic cycle of 19 years, equal to 235 lunations, was adopted, embracing an alternation of eight years (long familiar to the Greeks) with eleven 